\title{
EFFECT OF FASHION COMMUNICATION CHANNELS ON PSYCHOLOGICAL COMPATIBILITY WITH THE EGYPTIAN COMMUNITY TO UNIVERSITY FEMALE STUDENTS
}

Ola Ali Alwan OMAR*

Department of Garment and Textile, Faculty of Home Economics, Helwan University, Egypt

\begin{abstract}
This research aims to measure psychological compatibility levels with societal values in clothing to university Female students, and what media channel represent in the global fashion transport and their effect on dress behavior for individuals within the Egyptian society and through the application of search tools which represented as a questionnaire as a tool to gather information on the age and media channels which have an effect on the dress pattern with societal values on the sample of the number (240) of university female students. The test square $(Q)$ has been used to check the research, hypotheses and correlation coefficient (Spire Man). The results showed a correlation between psychological needs and the general level of compatibility with the societal values of clothing. As the results showed significant difference between levels of psychological compatibility and the societal values in clothing favor for the middle and low level of female students.

Keywords

Fashion, Communication Channels, Psychological, Egypt, Female Students.
\end{abstract}

\section{Introduction}

The language of clothing for thousands of years is the first tool that people used to communicate with each other, as a person speaks for himself through what he wears, as sociologists have indicated that the prevailing fashion (fashion) is also a symbolic language and a non-verbal system for communication, and the human behavior is as he sees it. Researchers refer to the process of interaction between the individual and society by means of relationships and symbols, and it is responsible for forming a network of human relationships that becomes capable of bringing about modification, change and reinforcement. Differentiation and choice situations occur in which values are formed, and it is generally the primary means of communication between individuals and groups. It is also the medium through which the idea, belief, principle, value and direction are transmitted. (1979 - Sproles) stated that the attitude towards fashion is motivated by various desires such as distinction or personal interest, assertion of self, love of ownership, improvement of appearance and rebellion, attraction of attention and social harmony. Others added that declaring personality, displaying wealth, imitation, and social unacceptability is illustrated by the dress code and is influenced by external and internal psychological factors. Therefore, the current research has identified the problem in that a large proportion of women accept outfits that do not correspond to the Egyptian societal values in clothing, and this problem is the result of the influence of

* Corresponding author: homeecon@helwan.edu.eg 
communication channels. Fashion and its compatibility with the psychological needs of individuals and due to the different psychological factors of women, the most important of which is age, so the current research has focused on the stage of university students.

\section{Research Problem:}

The research problem is determined by the following questions:

1- What are the levels of psychological compatibility with societal values in dress among university students?

2- Is there a statistically significant relationship between media and personal channels and the levels of conformity with societal values in the clothing of university students? .

3- What are the media and personal channels that have a moral relationship with the psychological needs of university students? .

4- What is the impression that the university student wants to announce to others about her clothes regarding levels of compatibility with societal values in clothing (high - medium - low)?

\section{Objectives of the Study:}

1- Measuring levels of compatibility with societal values in the mullahs of a sample of university students.

2- Knowing the media and personal channels that have an impact on the university student's dress code.

3- Study the relationship between media channels and the levels of agreement on societal values in dress among university students.

4- Knowing the impression that the university student wants to announce to others about her clothes.

\section{The Limits of the Study:}

Human Limits - This research was applied to female university students in the first and second grades from the age of (19-21) years. Objective boundaries: - Media and personal channels responsible for promoting fashions in clothing and determining levels of psychological compatibility with societal values in clothing. Spatial boundaries: (Faculties of home economics - Arts - Sciences) in the first and second year of Cairo governorate. Time limits: The field study was applied in the first semester of the academic year

\section{The Research Sample:}

It consists of girls in late adolescence between the ages of (12 - 21) years of university students. It consists of 240 female students chosen from different colleges (Faculty of Home Economics - Arts - Sciences) in the first and second year of the university stage (12 - 17) Year. The study sample was classified into three levels of psychological compatibility with societal values in 
dress.

Frequencies, percentages, average, and final scores for the answers of the three sections of the image test were counted to measure the level of general compatibility with societal values in clothing.

\section{Study Tools:}

1- Data collection form.

2- Psychological needs scale.

3- Image testing to measure the level of conformity with the societal values in the clothing.

Below is a presentation of the tools:

1- Information gathering form and consisted of:

- Personal information: - About age, major, school year, and fashion communication channels that have an impact on the students' dress style, namely:

A- Media Channels: TV fashion shows, fashion magazines, stores, display windows, clothes of famous personalities, and mail order magazines.

B- Personal channels: mothers, girlfriends, seeing others, seller, fashion designer.

C- The impression that the student wants to announce to others about her clothes.

2- Psychological needs scale related to clothing: -

The researcher prepared a scale that includes eighteen psychological needs, and each need represented by a psychological desire clarifies the intended need without mentioning it, and it was developed to clearly measure the desires of adolescent girls towards the psychological needs related to clothing. Validity of the scale: The researcher relied on the apparent validity of the scale by presenting it to experts in psychology. Stability of scale: The stability of the needs scale was calculated on an exploratory sample of (20 students) by the mid-segment method. And the equation (Spearman and Brown), and the result for the correlation coefficient is $(0,3)$, which indicates a strong correlation. Correction of the Psychological Needs Scale: The correction was made as follows:

A- He gave the answer (yes) three degrees, the answer (to some extent) two degrees, and the answer (no) one degree.

To arrange psychological needs, the cause of importance (important - medium importance not important), the grades were divided from grade (2) to grade (1) into three categories, and since class length $=$ range + number of categories. And range $=2$. The difference between the smallest value and the largest value $(-1)=$, and the number of classes $=$ if the length of the category $=(3+=0.66)$.

3- Image testing to measure compatibility with societal values in clothing: - 
- The researcher prepared a test that measures the levels of compatibility with societal values in clothing (high, medium, low) through the fashion designs that the student desires. The scale consists of the first and second sections that the students draw the designs they want and these desires are judged based on the opinion of experts in Psychology and Sociology. :

- The first section: - An open question for the student to draw three costumes that she desires for different occasions to be mapped by her, on the mannequin model drawn in front of her to facilitate the drawing process. Clarification of the design parts for the student's evaluation.

The second section: A question that is also open to answer. The student draws on a mannequin model, in front of which there are two costumes that find their designs suitable for a university student.

\section{Validate Scale:}

The researcher relied on the apparent validity of the scale by presenting it to psychology and sociology experts to ensure that the scale's costumes are included in compatibility with societal values in clothing.

\section{Stability of Scale:}

The image test consistency is calculated to measure compatibility with societal values in clothing on a pilot sample of (20 students) by the half-segmentation method using the equation (Spearman and Brown) and the result of the correlation coefficient is (0.3), which is a strong correlation. Correcting the image test to measure the level of conformity with the societal values in the clothes: The pictures were corrected based on the outfits desired by the students. Where it was classified according to the three levels of compatibility with societal values in clothing (high, medium and low).

\section{References}

1- Hamid Abdel Salam Zahran, Developmental Psychology - Childhood and Adolescence, 5th Edition, Dune Science, 2001.

2- Zainab Abdel-Hafeez Farghali youth clothing trends - Arab Thought House, 2001.

3- Saad Abdul-Rahman Human Behavior Analysis and Measurement of Kuwait's Variables, Al-Falah Library, 19.

4- Salih bin Abdullah bin Hamid and others, the Encyclopedia of Nazareth Al-Naim: On the Honorable Mentions of the Noble Messenger, Jeddah, Dar Al Wasila, 1418 AH.

5- Omar bin Abdul Rahman Al-Mufdi, Psychological needs of youth and the role of education in meeting them, Riyadh, Arab Education Office for the Gulf States, 1414 AH.

6- Lotfi Muhammad Park, Study of the Dressed Behavior of Adolescent Girls in Jeddah Governorate, Home Economics Seminar Jeddah - King Abdulaziz University, 180 AH. 
7 - Lamia Hassan on the attitudes of adolescents of both genders towards choosing their clothes and its relationship to some of their personal characteristics, Faculty of Home Economics Helwan University, 12.

8- Muhammad Atef Ghaith, Dictionary of Sociology, Alexandria House of Social Knowledge, 12

9- Mona Abdurrahman Abbas Abboud, The Relationship between Parental Attitudes and Attitudes of Adolescent Girls Toward Choosing Clothes, Faculty of Home Economics Helwan University, 12.

10- Nadia Mahmoud Khalil Tour, Women's TV programs in raising the level of dress awareness for Egyptian women, Faculty of Home Economics - Helwan University, 12.

11- Najat Muhammad Bawazeer, Study of Foundations of Choosing Teenage Girls' Clothes in Makkah Al-Mukarramah Governorate, Home Economics Seminar - Jeddah - King Abdulaziz University.

12- Hoda Sultan Al-Turki, a study of the relationships and trends in purchasing clothes for Saudi girls, a paper published in the Journal of Home Economics, Vol. 2, 12.

13- Alison Lurie, The language of clothes (London: Bloomsbury publishing Ltd, 1992. Changing Appearances: understanding dress in contemporary society (New York: Fairchild publications, 1994).

14- George B. Sproles and Leslie Davis Burns George B. Sproles Fashion consumer behavior to word dress (America: Burgess publishing company, 1979), 142.

15- Mary Brooks Picken The Fashion Dictionary (New York : Funk \& Wagnalls, 1973.

16- Zainab Abdel Hafiz FARGHALI and Asmaa Salah Ismail MUSTAFA, A PREPARATION OF AN EDUCATIONAL PROGRAM TO DRAW THE BASIC PATTERN FOR SKIRT BY USING MARVELOUS PROGRAM, International Journal of Design and Fashion Studies, Vol. 1, No. 1, 2018, pp. 1-7.

17- Yasmeen Muhammad AL-MANSI, Omnia Mahmoud IBRAHIM, AFRICAN ART AS A SOURCE OF CONTEMPORARY FASHION DESIGN, International Journal of Design and Fashion Studies, Vol. 1, No. 1, 2018, pp. 8-12.

Received: July 15, 2018

Accepted: September 20, 2018 